\title{
Platelets and Matrix Metalloproteinases: A Bidirectional Interaction with Multiple Pathophysiologic Implications
}

\author{
P. Gresele ${ }^{1}$ \\ E. Falcinelli ${ }^{1}$ \\ S. Momi ${ }^{1}$ \\ E. Petito ${ }^{1}$ \\ ${ }^{1}$ Department of Medicine and Surgery, Section of Internal and
Cardiovascular Medicine, University of Perugia, Perugia, Italy \\ Hämostaseologie 2021;41:136-145.
}

M. Sebastiano ${ }^{1}$

\begin{abstract}
Address for correspondence Paolo Gresele, MD, PhD, Department of Medicine and Surgery, Section of Internal and Cardiovascular Medicine, University of Perugia, Centro Didattico, Edificio B, Piano 1, 06132 Perugia, Italy (e-mail: paolo.gresele@unipg.it).
\end{abstract}

\begin{abstract}
Keywords

- matrix metalloproteinases

- platelet physiology

- atherosclerosis
\end{abstract}

Platelets contain and release several matrix metalloproteinases (MMPs), a highly conserved protein family with multiple functions in organism defense and repair. Platelet-released MMPs as well as MMPs generated by other cells within the cardiovascular system modulate platelet function in health and disease. In particular, a normal hemostatic platelet response to vessel wall injury may be transformed into pathological thrombus formation by platelet-released and/or by locally generated MMPs. However, it is becoming increasingly clear that platelets play a role not only in hemostasis but also in immune response, inflammation and allergy, atherosclerosis, and cancer development, and MMPs seem to contribute importantly to this role. A deeper understanding of these mechanisms may open the way to novel therapeutic approaches to the inhibition of their pathogenic effects and lead to significant advances in the treatment of cardiovascular, inflammatory, and neoplastic disorders.

\section{Introduction}

Matrix metalloproteinases (MMPs) are a family of zinc-dependent enzymes involved in many physiologic and pathologic phenomena regulated by extracellular matrix degradation, including tissue remodeling, cell migration, and angiogenesis. ${ }^{1}$ MMPs also affect several cell functions either by modifying chemokines and cytokines or by directly acting on cell surface receptors triggering cell signaling. ${ }^{1,2}$ While their role in disease has been widely explored, showing a central function in embryonic and skeletal disorders, cancer and metastasis, arthritis and central nervous system disorders, and cardiovascular disease, their interaction with blood platelets has been much less studied. Indeed, MMPs were first identified in the early 1960s by studies on the resorption of the tadpole tail and already in 1974 a collagenase activity was found in platelets, ${ }^{3}$ but it was not until a quarter of a century later that their effects on platelet function were discovered ${ }^{4}$ and only in the past 15 years their role in several pathophysiologic phenomena regulated by platelets have started to be unraveled. ${ }^{5}$ In parallel, the last few decades have witnessed to the great expansion of the understanding of the central role of platelets not only in hemostasis but also in immune response, inflammation and allergy, atherosclerosis, and cancer development, ${ }^{6}$ and MMPs seem to contribute importantly to this role. Here, we will shortly review the presence of MMPs in platelets, their role in platelet functions, and the effect of platelet MMPs on other cells and tissues in disease.

\section{Matrix Metalloproteinases and Platelet Function}

Megakaryocytes carry mRNA transcripts for up to 10 different MMPs and platelets contain several MMPs and tissue inhibitors which are implicated in hemostasis modulating platelet function ( - Table 1$)^{5,7-9}$

Resting platelets constitutively express MMP-1 $\left(16.5 \pm 7.2 \mathrm{ng}\right.$ per $1 \times 10^{9}$ cells), primarily as pro-MMP-1, received

December 4, 2020

accepted after revision

February 15, 2021 (c) 2021. Thieme. All rights reserved. Georg Thieme Verlag KG,

Rüdigerstraße 14,

70469 Stuttgart, Germany
DOI https://doi.org/ 10.1055/a-1393-8339. ISSN 0720-9355. 
Table 1 Interactions between MMPs and platelets

\begin{tabular}{|c|c|c|c|c|}
\hline MMP & Alternative name & Localization in platelets & Role in platelet function & References \\
\hline MMP-1 & Collagenase type I & Granules/Cytoplasm & $\begin{array}{l}\text { Primes platelets, cleaves PAR1 (at site } D_{39} \downarrow P_{40} \text { ), } \\
\text { activates platelet signaling, increases thrombus } \\
\text { formation }\end{array}$ & $10-12$ \\
\hline MMP-2 & $\begin{array}{l}\text { Gelatinase A; } \\
72 \text { kDa Gelatinase; } \\
\text { type IV collagenase }\end{array}$ & Granules/Cytoplasm & $\begin{array}{l}\text { Primes platelets, cleaves PAR1 (at TL38 } \downarrow \text { D39PR), } \\
\text { activates platelet signaling, increases thrombus } \\
\text { formation }\end{array}$ & $4,13,17,38$ \\
\hline MMP-3 & $\begin{array}{l}\text { Stromelysin-1; } \\
\text { proteoglycanase }\end{array}$ & Granules/Cytoplasm & No effects & 10 \\
\hline MMP-9 & $\begin{array}{l}\text { Gelatinase B; } \\
92 \text { kDa gelatinase }\end{array}$ & Plasma-derived & Decreases activation. Reduces $\mathrm{Ca}^{2+}$ mobilization & $21-24$ \\
\hline MMP-12 & $\begin{array}{l}\text { Macrophage } \\
\text { metalloelastase }\end{array}$ & Granules/Cytoplasm & $\begin{array}{l}\text { Cleaves CEACAM1, facilitates adhesion to } \\
\text { type I collagen, platelet aggregation, } \\
\text { and } \alpha \text { granule secretion }\end{array}$ & 25 \\
\hline MMP-13 & Collagenase type III & Plasma-derived (?) & $\begin{array}{l}\text { Impaired platelet aggregation to } \\
\text { low-dose collagen, CRP. } \\
\text { Reduced thrombus formation }\end{array}$ & $26-28$ \\
\hline MMP-14 & MT1-MMP & Membrane & Inhibits thrombus growth and stability & 29 \\
\hline
\end{tabular}

Abbreviations: MMP, matrix metalloproteinase; MT, membrane-type; PAR, protease-activated receptor.

which is released and transformed into the active form upon thrombin stimulation. ${ }^{10}$ Released MMP- 1 colocalizes with $\beta_{3}$ integrins on activated platelets at cell-to-cell contact sites, and also binds to the $\alpha_{2} I$ domain of integrin $\alpha_{2} \beta_{1}$ through its linker and hemopexin motifs. ${ }^{11}$ MMP-1 regulates outside-in signaling in platelets by clustering $\beta_{3}$ integrins, inducing tyrosine phosphorylation of intracellular proteins and priming platelets for aggregation. ${ }^{10}$ MMP-1 promotes platelet thrombus formation on collagen-coated surfaces at arterial flow rates, a phenomenon blocked by MMP-1 or PAR1 inhibitors. $^{12}$

Platelets also contain pro-MMP-2 $\left(17.3 \pm 3.7 \mathrm{ng} / 10^{8}\right.$ platelets) which upon stimulation translocates to the platelet surface where it gets activated and in part released. ${ }^{4,13}$ The presence of MMP-2 in platelets of Gray platelet syndrome patients, which lack $\alpha$-granules, suggests that this protease is not granular ${ }^{14}$ but probably cytoplasmic. ${ }^{15}$ Active MMP-2 does not induce platelet aggregation but amplifies the activation response to a wide range of agonists, suggesting that its effects are mediated by the activation of a common, post-receptorial signaling pathway. ${ }^{4,13}$ The concentrations of MMP-2 exerting this priming activity $(0.1-50 \mathrm{ng} / \mathrm{mL}$, i.e., $0.0015-$ $0.75 \mathrm{nM}$ ) are in the range of those secreted by activated human platelets in vitro and in vivo. ${ }^{13,16}$

Platelet adhesion to fibrinogen is associated with the release of MMP-2 and phenanthroline, an unspecific MMP inhibitor, reduces platelet adhesion suggesting that MMP-2 promotes adhesion. ${ }^{17}$ Indeed, active MMP-2 enhances shear stress-induced platelet activation and thrombus formation on collagen and it acts as an adhesive substrate per se. ${ }^{18}$ MMP-2 is thus likely to play a relevant role in thrombus formation at the sites of increased shear stress in vivo, like in stenosed atherosclerotic coronary arteries. ${ }^{19}$
On the other hand, a recent study suggested that MMP-2 could blunt NOX2 activity and ROS formation in platelets possibly downregulating reactivity in oxidative stress conditions. $^{20}$

Conflicting results exist concerning the presence of MMP9 in platelets. Activated platelets bind MMP-9, suggesting that when MMP-9 is detected in platelets it is probably plasma-derived. ${ }^{21}$ Moreover, contamination by white blood cells, which are very rich in MMP-9, may explain the presence of MMP-9 in platelet preparations. ${ }^{22,23}$ Active MMP-9 was reported to counteract the platelet-potentiating effects of MMP- $2^{17}$ at concentrations (15-90 ng/mL) in the range of those found in plasma $(30-50 \mathrm{ng} / \mathrm{mL}) .^{24}$

There are discordant findings concerning the presence of MMP-3 in platelets and megakaryocytes, and no effects on platelet function were reported; thus, its role for platelets is still awaiting clarification. ${ }^{10}$

Expression of MMP-12 in human platelets was also recently reported and shown to mediate carcinoembryonic antigen-related cell adhesion molecule 1 (CEACAM1) shedding from their surface generating a peptide which facilitates adhesion to type I collagen, aggregation, and $\alpha$-granule secretion. ${ }^{25}$

MMP-13, a collagenolytic metalloproteinase not present in platelets but upregulated in atherosclerotic and inflammatory tissue, ${ }^{26}$ was reported to reduce thrombus formation on fibrillar collagen under flow through the partial digestion of collagen monomers, suggesting that MMP-13 may inhibit platelet recruitment at ruptured plaques. ${ }^{27}$ However, these findings were obtained with rather high concentrations of MMP-13 $(80 \mathrm{nM})$ and are thus of uncertain physiological meaning. ${ }^{28}$

Platelets express MT1-MMP (MMP-14) which forms a trimolecular complex with pro-MMP-2 and TIMP-2 (the 
physiologic inhibitor of MMP-2) on the platelet surface allowing the generation of active MMP-2. ${ }^{29}$

Recently, it has been shown that resting platelets express on their surface the extracellular MMP inducer EMMPRIN (CD147), an immunoglobulin-like receptor known for its ability to induce MMPs expression. Its expression is upregulated in vitro upon platelet activation with several stimuli. ${ }^{30}$

\section{Biochemical Mechanisms}

Catalytically active MMP-1 cleaves the platelet PAR1 exodomain at $\mathrm{LD}^{39} / \mathrm{P}^{40} \mathrm{RSFL}$, two amino acid residues upstream the thrombin cleavage site $\left(\mathrm{R}^{41}-\mathrm{S}^{42}\right)$, triggering G12/13-Rho-GTP signaling. MMP-1 also enhances protein tyrosine phosphorylation, and namely of p38MAPK and its substrate MAPKAP-K2 involved in cytoskeletal reorganization. ${ }^{12}$

Also active MMP-2 enhances platelet activation by enzymatically cleaving PAR1 at a specific, noncanonical extracellular site, different from that of both MMP-1 and thrombin, by an $\alpha_{\text {IIb }} \beta_{3}$-facilitated mechanism. The cleavage of PAR1 generates a tethered ligand different from that produced by thrombin that in turn triggers biased PAR1 signaling. This explains why MMP2 , although initiating intraplatelet signaling, requires $G_{i}$ activation triggered by other agonists to start aggregation. ${ }^{31}$ Active MMP-2 amplifies platelet activation by triggering the post-receptorial signaling pathway phosphatidyl-inositol 3kinase (PI-3-K). ${ }^{13}$ A direct interaction between $\alpha_{\mathrm{v}} \beta_{3}$ and MMP2 was shown on the surface of melanoma cells with the formation of a stable MMP-2 integrin $\alpha_{v} \beta_{3}$ complex dependent on the C-terminus of MMP-2. ${ }^{32}$ MMP-2 interacts also with integrin $\alpha_{\mathrm{II}} \beta_{3}$ on activated platelets via the C-terminal hemopexin-like domain and this interaction is required for platelet activation. $^{31,33}$

MMP-2 was also reported to play an intracellular function in platelets by hydrolyzing talin, a cytoskeletal protein required for the inside-out activation of $\alpha_{\mathrm{IIb}} \beta_{3} .{ }^{34}$ Finally, MMP-2 upregulates glycoprotein (GP)Ib receptor expression, thus potentiating the adhesion to VWF, but also the affinity of VWF for GPIb by proteolytic modification of the former. ${ }^{35}$

The platelet-inhibitory activity of activated MMP-9 may be due to the inhibition of phospholipase $\mathrm{C}$, with consequent suppression of phosphoinositide breakdown, protein kinase $C$ activation, thromboxane $\mathrm{A} 2$ formation, and intracellular $\mathrm{Ca}^{2+}$ mobilization, ${ }^{36}$ and to the formation of nitric oxide which acts as a negative feedback regulator of platelet activation. ${ }^{37}$
Relatively high MMP-13 concentrations were reported to bind platelet $\alpha_{\mathrm{II}} \beta_{3}$ and GPVI but without triggering platelet degranulation or $\alpha_{\mathrm{IIb}} \beta_{3}$ activation, thus not starting intraplatelet signaling. ${ }^{28}$ On the other hand, we showed that physiologic concentrations of active MMP-13 stimulate human platelets and thrombus formation in mice. ${ }^{38}$

Finally, resting platelets express latent MT1-MMP on their surface which is activated upon collagen stimulation, suggesting that MT1-MMP may contribute to collagen-induced platelet aggregation. ${ }^{29}$

Platelet stimulation with recombinant EMMPRIN-Fc induced surface expression of CD40L and P-selectin, suggesting that EMMPRIN-EMMPRIN interaction activates platelets. ${ }^{30}$ Soluble CD147 binds to platelet GPVI with high affinity and this interaction mediates platelet rolling. ${ }^{39}$ Moreover, CD147 is the major receptor of cyclophilin A, a proinflammatory cytokine expressed in a wide variety of cell types, including platelets, and tissues. Extracellular cyclophilin A activates platelets via EMMPRIN, inducing platelet degranulation depending on phosphoinositide-3-kinase/Akt signaling. ${ }^{40}$

\section{Studies in Animals}

In an ex vivo model of platelet activation on collagen under flow, platelet thrombi were smaller when blood from MMP$2^{-I-}$ mice was employed as compared with blood from wildtype mice. ${ }^{21}$ In contrast, perfusion of blood from $\mathrm{MMP}^{-9^{-1-}}$ mice resulted in thrombi covering a larger surface, and blood from MMP- $3^{-1-}$ mice did not behave differently from wildtype mice (- Table 2 ). ${ }^{21}$

Platelet pulmonary thromboembolism induced by the i.v. injection of collagen + epinephrine and femoral artery thrombosis induced by photochemical damage were reduced in MMP- $2^{-1-}$ mice. Thrombus formation was delayed also in chimeric mice lacking MMP-2 only in platelets, indicating that it is platelet-derived MMP-2 that facilitates thrombus formation. Finally, arterial thrombus formation at the site of mild vascular injury in mice was triggered by plateletreleased MMP-2 which may thus transform a normal hemostatic response to vessel injury into thrombosis. ${ }^{41}$ This observation might explain why in the coronary bed of patients dying from acute myocardial infarction (MI), several fissured or eroded plaques are found, but only one occluding thrombus forms and is ultimately responsible for the acute ischemic event ( - Table 2 ). ${ }^{42}$

Table 2 Summary of the results concerning platelet-related phenomena obtained in animal models

\begin{tabular}{|l|l|l|}
\hline Mouse strain & Platelet-related effects & References \\
\hline MMP-2-I- $^{-1}$ & - Reduced platelet thrombi ex vivo & 21,41 \\
& - Reduced collagen + epinephrine-induced lung thromboembolism & 41 \\
& - Reduced photochemically induced arterial thrombosis & 41 \\
& Enhanced abdominal aortic aneurysms & 41,48 \\
\hline MMP-9-I- $^{-1}$ & - Increased platelet thrombi ex vivo & 21 \\
\hline MMP-3-I- & Enhanced abdominal aortic aneurysms & 44,45 \\
\hline
\end{tabular}

Abbreviation: MMP, matrix metalloproteinase. 
MMPs play a crucial role in atherogenesis. MMP-2 degrades elastin-generating peptides which accelerate low-density lipoprotein (LDL) oxidation and calcification. ${ }^{43}$ MMP-2 and MMP-9 produced by macrophages and mesenchymal-derived cells in the adventitia and media of the aorta contribute also to the initiation and progression of abdominal aortic aneurysms (AAAs) by degrading elastin fibers. ${ }^{44,45}$ The deletion of MMP-2 and MT1-MMP genes reduced AAA formation in mice (-Table 2). ${ }^{45-47}$ Treatment with aspirin and clopidogrel, inhibiting platelet activation, significantly decreased aortic tissue MMP-2 in a mouse model of angiotensin II-induced AAA, suggesting that circulating activated platelets play a role in MMP-2 accumulation in the aortic wall. $^{48}$

Recently, we generated a novel mouse model of spontaneous AAA formation (LDL receptor [LDL-R]/endothelial nitric oxide synthase (eNOS $)^{-1-}$ mice), strictly recapitulating human AAA, showing that platelets are essential for the migration of inflammatory cells into the aortic vessel wall and that a significant fraction of the MMP-2 found in AAA extracts derives from an enhanced production by vascular smooth muscle cells generated by the contact with platelets infiltrating aorta. ${ }^{49}$

Platelet-derived CD40L is a potent inducer of lung neutrophil infiltration in abdominal sepsis-induced lung injury. In turn, neutrophil-derived MMP-9 induces CD40L shedding from platelets triggering a vicious circle crucial for the pathogenic consequences of sepsis in mice. ${ }^{50}$

Platelets are involved in tumor metastasis in bone. Platelets regulate bone formation triggered by tumor cells through the uptake of tumor-derived proteins, including several MMPs (MMP-1, MMP-3, MMP-13, TIMP-1, and TIMP-2), and through the secretion of $\alpha$-granule proteins favoring osteoblast differentiation. In a xenograft tumor model of human prostate cancer in immunocompromised mice, the neutralization of MMP-1, MMP-3, and MMP-13 released by platelets using specific antibodies or marimastat inhibited bone formation in response to tumor growth. ${ }^{51}$

The role of MMP-1 and MMP-14 in regulating platelet function and the interactions with other cells in vivo has not been investigated in mice because murine platelets do not express MMP-1, ${ }^{52}$ while MMP-14-deficient mice are not vital.

EMMPRIN gene silencing is associated with aberrant extracellular matrix remodeling, characterized by a striking reduction of age-associated fibrosis resulting in dilated cardiomyopathy in aging mice. ${ }^{53}$

\section{Studies in Humans}

Platelet MMP-1 is released upon interaction with Streptococcus sanguinis, a predominant bacterium of the oral cavity associated with the development of infective endocarditis; thus, it may participate in the cardiovascular complications related to this infection. ${ }^{54}$

Platelets release MMP-2 in vivo in healthy humans during primary hemostasis, suggesting that MMP-2 plays a physiological role in the regulation of the platelet response to vessel wall damage. MMP-2 concentrations in shed blood were significantly higher than in venous blood and increased progressively, consistent with ongoing platelet activation. Active MMP-2 in shed blood was in the range of concentrations (around $1 \mathrm{ng} / 10^{8}$ platelets) found to potentiate platelet activation. ${ }^{16}$ Patients with acute coronary syndromes (ACSs) showed enhanced concentrations of total and active MMP-2 in blood from the coronary artery carrying the culprit lesion compared with peripheral blood, and plasma obtained from coronary blood potentiated the activation of control platelets, an effect suppressed by TIMP-2, suggesting a role for MMP-2 in sustained platelet activation during ACS. ${ }^{19}$ Atherosclerotic plaques contain high amounts of MMP-2 ${ }^{55-57}$ and recently we showed that human carotid plaque extracts promote platelet aggregation due to their content of active MMP-2, an effect prevented by specific MMP-2 inhibitors. Moreover, elevated MMP-2 activity in plaques and high aggregation-potentiating plaques were associated with a higher rate of subsequent ischemic cerebrovascular events, suggesting that MMP-2 contained in plaques participates in platelet thrombus formation. ${ }^{58}$

MMP-3 plays an important role in several pathologic processes such as rheumatoid arthritis, systemic lupus erythematosus, and atherosclerosis, ${ }^{59-61}$ in which platelets are also involved ${ }^{62-64}$; thus, future studies should focus on the role of platelet-derived MMP-3 in these disorders.

Platelet-derived MMP-9 has been implicated in inflammatory disorders. MMP-9 platelet content and release are increased in Crohn's disease, ${ }^{65}$ a chronic inflammatory bowel disorder, and Behçet's disease, ${ }^{66}$ an autoimmune vasculitis, and induce the shedding of platelet CD40L (sCD40L) which in turn causes endothelial activation. ${ }^{65-67}$ Finally, a significant correlation exists between plasma concentrations of CRP and MMP-9 in the coronary circulation of ACS patients, suggesting a link between inflammation and plaque rupture. $^{68}$

EMMPRIN has been shown to participate in the induction of proinflammatory and prothrombotic effects in patients with $\mathrm{MI}$ and in $\mathrm{ApoE}^{-1-}$ mice: recent studies have highlighted a role for platelet CD147 in plaque formation, monocyte recruitment, cytokine release, and foam cell formation. ${ }^{69-71}$ CD147 expression has also been observed in atheromatous plaques in association with MMP-9 expression. ${ }^{72}$ Moreover, circulating levels of soluble CD147 correlated with soluble glycoprotein VI in plasma, a platelet-specific marker in healthy subjects and patients with coronary artery disease. ${ }^{73}$ Thus, EMMPRIN is considered a novel potential target to reduce vascular inflammation and atherosclerotic lesion development.

\section{Inhibition of MMPs as a Therapy for Cardiovascular Disease}

The studies summarized earlier lend compelling evidence to the hypothesis that MMP inhibition may represent a novel therapeutic approach to the prevention of atherosclerotic plaque instability, MI, and stroke. Numerous synthetic selective and nonselective MMP inhibitors (MMPi) have indeed been created and pursued as therapeutic agents. Some have 
Table 3 MMPi as potential tools for the treatment of cardiovascular disease

\begin{tabular}{|c|c|c|c|c|c|}
\hline MMPi & Specificity & Animal models & Human studies & Effects & References \\
\hline CGS 27023A & Broad-spectrum & $\begin{array}{l}\text { Progression of athero- } \\
\text { sclerosis, aneurysm, } \\
\text { and restenosis in LDL- } \\
\mathrm{R}^{-1-} \text { mice }\end{array}$ & & $\begin{array}{l}\text { No prevention of plaque } \\
\text { development or pro- } \\
\text { gression; retardation of } \\
\text { the progression of } \\
\text { aneurysm }\end{array}$ & 76 \\
\hline RS-130830 & Broad-spectrum & $\begin{array}{l}\text { Plaque development } \\
\text { and stability in ApoE } \\
\text { mice }\end{array}$ & & $\begin{array}{l}\text { No change in the inci- } \\
\text { dence of plaque rupture }\end{array}$ & 77 \\
\hline PG-116800 & $\begin{array}{l}\text { MMP-2, }-3,-8, \\
-9,-13, \text { and }-14\end{array}$ & & $\begin{array}{l}\text { PREMIER (Prevention of } \\
\text { Myocardial Infarction } \\
\text { Early Remodeling) in } \\
\text { post-MI patients }\end{array}$ & $\begin{array}{l}\text { No improvement in } \\
\text { echocardiographic or } \\
\text { clinical outcomes }\end{array}$ & 78 \\
\hline \multirow[t]{5}{*}{ Doxycycline } & Broad-spectrum & $\begin{array}{l}\text { Ischemic heart in } \\
\text { Sprague-Dawley rats }\end{array}$ & & $\begin{array}{l}\text { Improves endothelial } \\
\text { dysfunction post-MI }\end{array}$ & 80 \\
\hline & & $\begin{array}{l}\text { Angll-induced athero- } \\
\text { sclerosis in } \mathrm{LDL}^{-1-} \mathrm{R}^{-} \\
\text {mice }\end{array}$ & & $\begin{array}{l}\text { Reduces the incidence } \\
\text { of AAA }\end{array}$ & 81 \\
\hline & & & $\begin{array}{l}\text { Pilot clinical trials in } \\
\text { patients with } \\
\text { symptomatic carotid } \\
\text { artery disease }\end{array}$ & $\begin{array}{l}\text { No positive effects on } \\
\text { plaque phenotype and } \\
\text { atheroma progression }\end{array}$ & 82 \\
\hline & & & $\begin{array}{l}\text { MIDAS pilot trial (in } \\
\text { patients with coronary } \\
\text { artery disease) }\end{array}$ & $\begin{array}{l}\text { No prevention of plaque } \\
\text { rupture events }\end{array}$ & 83 \\
\hline & & & $\begin{array}{l}\text { TIPTOP trial } \\
\text { (in patients with } \\
\text { myocardial infarction) }\end{array}$ & $\begin{array}{l}\text { Reduces end-diastolic } \\
\text { volumes, infarct size, } \\
\text { and infarct severity }\end{array}$ & 84 \\
\hline Minocycline & MMP-9 & & $\begin{array}{l}\text { MINOS trial (in patients } \\
\text { with stroke treated with } \\
\text { rt-PA) }\end{array}$ & $\begin{array}{l}\text { Decreases plasma MMP- } \\
9 \text { levels (associated with } \\
\text { the risk of tPA-related } \\
\text { hemorrhage) }\end{array}$ & 85 \\
\hline RXP470.1 & MMP-12 & $\begin{array}{l}\text { Progression of } \\
\text { atherosclerosis in } \\
\text { ApoE }{ }^{-/-} \text {mice }\end{array}$ & & $\begin{array}{l}\text { Retards atherosclerotic } \\
\text { plaque development }\end{array}$ & 86 \\
\hline SB-3CT & MMP-2, MMM-9 & $\begin{array}{l}\text { Cerebral ischemia in } \\
\text { mice }\end{array}$ & & $\begin{array}{l}\text { Prevention of brain } \\
\text { damage }\end{array}$ & 89,90 \\
\hline
\end{tabular}

Abbreviations: AAA, abdominal aortic aneurysm; LDL-R, low-density lipoprotein receptor; MI, myocardial infarction; MMP, matrix metalloproteinases; MMPi, MMP inhibitors.

been tested in animal models, but few have made their way to clinical trials and mostly in the oncology field. ${ }^{74}$

The potential of MMPi for the treatment of cardiovascular disease has been evaluated in several studies (-Table 3$)^{75}$

\section{Direct Matrix Metalloproteinase Inhibitors}

Zinc group-chelating inhibitors (such as thiol or hydroxamate or tetracycline derivatives) have given results far from encouraging. Nonselective hydroxamic acid-based MMPi did not prevent plaque development or progression in LDL-R or ApoE knockout mice. ${ }^{76,77}$

PG-116800, an oral MMPi of the hydroxamic acid class with high affinity for MMP-2, $-3,-8,-9,-13$, and -14 , was studied in the phase II double-blind, multicenter randomized control trial PREMIER (Prevention of Myocardial Infarction Early Remodeling) in post-MI patients, but it did not show improvement in echocardiographic or clinical outcomes. $^{78}$

Other studies were performed with the widely used antibiotic doxycycline which, at sub-antimicrobial doses, displays broad-spectrum MMPi properties. ${ }^{79}$ In a study in rats, doxycycline reduced MMP-2 activity in left ventricular extracts and improved endothelial dysfunction post-MI. ${ }^{80}$ Another study testing the effect of doxycycline on the development of angiotensin II-induced atherosclerosis and AAA formation in LDL- $\mathrm{R}^{-1-}$ mice showed no effect on the extent of atherosclerosis but a markedly reduced incidence of AAA, showing that MMPs are crucially involved in AAA formation. ${ }^{81}$

In two independent, prospective placebo-controlled pilot clinical trials in patients with symptomatic carotid ${ }^{82}$ or coronary artery disease (MIDAS pilot trial) ${ }^{83}$ undergoing intervention, treatment with doxycycline failed to exert 
positive effects on plaque phenotype, atheroma progression, ${ }^{82}$ or clinical outcome. ${ }^{84}$ However, some limitations of these studies should be considered: patients received doxycycline for variable times before surgery and only subjects with recent ACS were studied. ${ }^{83}$ Moreover, although the MIDAS trial did not show differences in the primary clinical endpoint, 6 months of doxycycline reduced heart dysfunction and CRP and IL-6, which are markers of inflammation. ${ }^{83}$

In the phase II TIPTOP trial in patients with MI, treatment with doxycycline ( $100 \mathrm{mg}$ twice daily) reduced end-diastolic volumes, infarct size, and infarct severity in comparison to standard treatment. ${ }^{84}$

Minocycline, a semisynthetic tetracycline able to bind MMPs due to its affinity for $\mathrm{Zn}^{2+}$, administered to patients with stroke treated with rt-PA decreased plasma MMP-9 levels, which are associated with the risk of tPA-related hemorrhage, showing promise for the prevention of the adverse consequences of thrombolytic therapy. ${ }^{85}$

A phosphinic peptide (RXP470.1) that is a potent, selective murine MMP-12 inhibitor, significantly retarded atherosclerotic plaque development in ApoE knockout mice. ${ }^{86}$

A highly selective small molecule inhibitor of MMP-9, JNJ0966, which prevents conversion of the MMP-9 zymogen into the catalytically active enzyme, showed effectiveness in reducing disability scores in a mouse model of neuroinflammation. ${ }^{87}$

SB-3CT, a selective inhibitor of MMP-2 and -9 which binds the active site of gelatinases, ${ }^{88}$ showed promise in the prevention of brain damage caused by cerebral ischemia in mice. $^{89,90}$

Finally, SP-8356, a synthetic small molecule with antiinflammatory and antioxidative activities, reduces plaque progression and stabilizes vulnerable plaques in ApoE-deficient mice, inhibiting CD147-cyclophilin A interactions ${ }^{91}$ and reducing neointimal hyperplasia through inhibition of MMP-9 activity in Sprague-Dawley rats. ${ }^{92}$

\section{Indirect Matrix Metalloproteinase Inhibitors}

Several cardiovascular drugs act as indirect inhibitors of MMPs.

The catalytic domain of ACE is similar to that of MMPs; thus, ACE inhibitors display an inhibitory effect on some MMPs. ${ }^{93}$ For example, captopril and lisinopril inhibit MMP-2 activity at concentrations greater than 4 and $1 \mathrm{mmol} / \mathrm{L}$, respectively, whereas MMP-9 was inhibited by captopril at $87 \mathrm{nmol} / \mathrm{L} .{ }^{94,95}$ ACE inhibitors improve post-MI outcomes ${ }^{96}$ and part of this action might be due to MMP inhibition. ${ }^{97}$

Similarly to ACE inhibitors, angiotensin II receptor antagonists inhibit MMPs and improve ECM remodeling. Rats treated with losartan showed reduced mRNA transcription and protein expression of MMP-2 and MMP-9 in atherosclerotic lesions. ${ }^{98}$ Treatment with valsartan decreased levels of MMP-2, -3 , and -9 post-MI in rats. ${ }^{99}$ Moreover, patients treated with trandolapril and valsartan showed reduced MMP-9 plasma levels and LV remodeling post-MI. ${ }^{100}$

The $\beta$-adrenergic receptor antagonist atenolol decreased MMP activity and improved LV stiffness in an experimental heart failure model in dogs. ${ }^{101}$ Rats treated with metoprolol showed decreased MMP-2 mRNA levels and decreased cardiac oxidative stress markers post-MI. ${ }^{102}$ Similar results were observed in post-MI pigs treated with carvedilol or metoprolol, both of which decreased MMP-2 activity, MCP-1 expression, and macrophage infiltration. ${ }^{103}$ Finally, patients with heart failure treated with carvedilol showed reduced MMP-9 activity in plasma. ${ }^{104}$

Statins (hydroxymethylglutaryl coenzyme A [HMG-CoA] reductase inhibitors) exert a variety of pleiotropic effects, including the inhibition of expression of various MMPs (e.g., MMP-2 and MMP-9) in atheromatous plaques by reducing vascular inflammation. ${ }^{105}$ Patients with MI treated with pravastatin showed decreased MMP-2 and MMP-9 serum levels. ${ }^{106-108}$ Also, in a rat model of heart failure, pravastatin suppressed myocardial MMP-2 and MMP-9. ${ }^{109}$

Very few data are available on the effects of MMP inhibition on platelets. Platelet-derived MMP-1 secretion is inhibited by pretreatment with aspirin and GPIb and GPIIb/IIIa antagonists. $^{12}$

Neutralization of MMP-2 by blocking antibodies, recombinant TIMP-2, or MMPi reduced collagen-induced platelet aggregation, indicating that platelet-released MMP-2 mediates aggregation. ${ }^{4,13}$ On the other hand, aspirin did not inhibit in vivo release of MMP-2 in humans ${ }^{16}$ and did not prevent MMP-2-induced platelet potentiation. ${ }^{13,16,19,110}$

Recently, by the application of the nanobody technology, we generated a highly selective inhibitor of MMP-2 that completely abolished the potentiating activity of MMP-2 on human platelet activation. ${ }^{111}$ This new nanotechnological tool may show promise for the study of the role of MMP-2 in cardiovascular pathophysiology.

\section{Conclusions}

Blood platelets have phylogenetically evolved as a highly specialized cell devoted to the maintenance of hemostasis, a vital function of blood, but they retain several other functions of their ancestor cells, the hemocytes which played both the role of arresting hemorrhage and of fighting invading pathogens. ${ }^{112}$ MMPs are a highly conserved protein family originated probably before the emergence of vertebrates from invertebrates, ${ }^{113}$ with multiple functions in organism defense. It is thus reasonable to expect that the interaction between platelets and MMPs regulates multiple pathophysiologic phenomena related to the hemostatic and immunologic systems in humans ( - Fig. 1). ${ }^{5,114}$

While great progress in the understanding of these interactions has been made in the last few years, the translation into clinical applications is lagging behind and MMP biomarkers for cardiovascular disease or MMPi as antiplatelet or antiatherosclerotic therapies have not entered clinical use yet.

Further insight into the molecular mechanisms regulating the interactions between platelets and MMPs and innovative approaches to the inhibition of their pathogenic effects may lead to significant advances in the treatment of cardiovascular, inflammatory, and tumor disorders. 


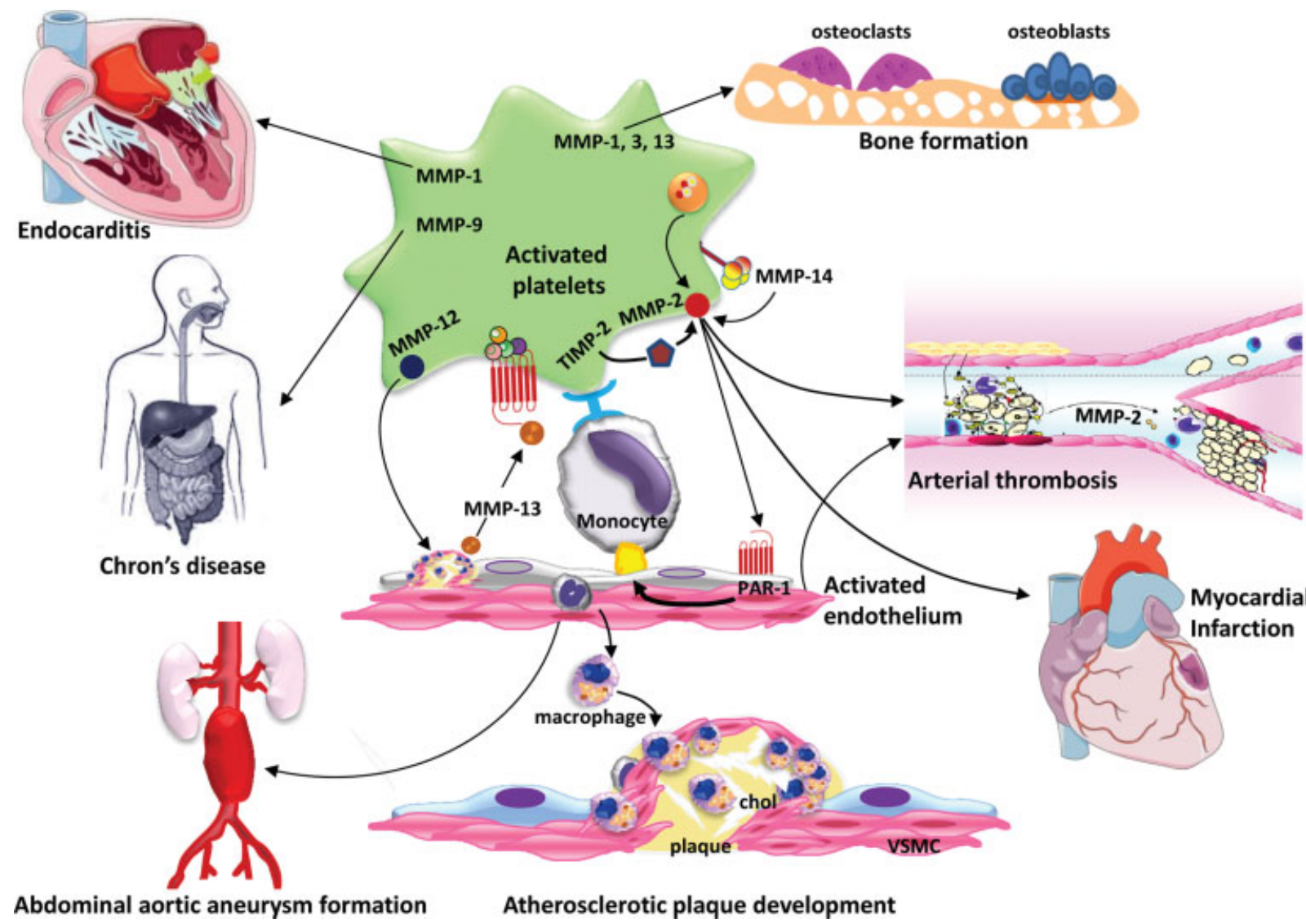

Fig. 1 Role of platelet-derived MMPs in disease. Platelets contain, release, and/or express on their surface upon activation several MMPs, including MMP-1, -2, -3, -9, -12, -13, and MT1-MMP (MMP-14). Platelet-derived MMP-1, -3, and -13 regulate bone formation triggered by tumor cells, stimulating osteoblasts proliferation and differentiation. MMP-2 contained in atherosclerotic plaques contributes to platelet activation, thus further stimulating thrombus formation. On the other hand, platelet-released MMP-2 facilitates thrombus formation at mild injury sites. MT1-MMP (MMP-14) allows the generation of active MMP-2 on the platelet surface. Platelet-derived active MMP-2, acting on PAR-1 of endothelial cells, induces endothelial activation with consequent increase of VCAM-1 expression triggering monocyte transmigration, thus promoting atherosclerotic plaque formation. Similarly, platelet-derived MMP-2 induces abdominal aortic aneurysm formation, enhancing MMP-2 levels in the abdominal aorta. Platelets contain and release MMP-12, and MMP-12 has a role in atherosclerosis. Platelet-released MMP-9 induces the shedding of platelet CD40L in Crohn's disease, a chronic inflammatory bowel disease, and might be responsible, at least in part, for the high state of activation of platelets from these patients. The release of platelet MMP-1 in response to Streptococcus sanguinis, a bacterium associated with the development of infective endocarditis, may link platelet activation with the cardiovascular complications related to this infection. chol, cholesterol; PAR-1, protease-activated receptor-1; TIMP-2, tissue inhibitor of metalloproteinases-2; VSMCs, vascular smooth muscle cells.

\section{Conflict of Interest}

The authors declare that they have no conflict of interest.

\section{Acknowledgments}

This work was supported by a research grant from Cariplo to P.G. (protocol no. 2018-0483) and by a fellowship from Fondazione Umberto Veronesi to E.F.

\section{References}

1 Cui N, Hu M, Khalil RA. Biochemical and biological attributes of matrix metalloproteinases. Prog Mol Biol Transl Sci 2017; 147:1-73

2 Van Lint P, Libert C. Chemokine and cytokine processing by matrix metalloproteinases and its effect on leukocyte migration and inflammation. J Leukoc Biol 2007;82(06):1375-1381

3 Chesney CM, Harper E, Colman RW. Human platelet collagenase. J Clin Invest 1974;53(06):1647-1654

4 Sawicki G, Salas E, Murat J, Miszta-Lane H, Radomski MW. Release of gelatinase A during platelet activation mediates aggregation. Nature 1997;386(6625):616-619
5 Gresele P, Falcinelli E, Sebastiano M, Momi S. Matrix metalloproteinases and platelet function. Prog Mol Biol Transl Sci 2017; 147:133-165

6 Gresele P, Kleiman NS, Lopez JA, Page CP, eds. Platelets in Thrombotic and Non-Thrombotic Disorders: An update. Springer International Publishing; 2017

7 Santos-Martínez MJ, Medina C, Jurasz P, Radomski MW. Role of metalloproteinases in platelet function. Thromb Res 2008;121 (04):535-542

8 Malara A, Ligi D, Di Buduo CA, Mannello F, Balduini A. Subcellular localization of metalloproteinases in megakaryocytes. Cells 2018;7(07):80

9 Cecchetti L, Tolley ND, Michetti N, Bury L, Weyrich AS, Gresele P. Megakaryocytes differentially sort mRNAs for matrix metalloproteinases and their inhibitors into platelets: a mechanism for regulating synthetic events. Blood 2011;118(07): 1903-1911

10 Galt SW, Lindemann S, Allen L, et al. Outside-in signals delivered by matrix metalloproteinase- 1 regulate platelet function. Circ Res 2002;90(10):1093-1099

11 Stricker TP, Dumin JA, Dickeson SK, et al. Structural analysis of the alpha(2) integrin I domain/procollagenase-1 (matrix 
metalloproteinase-1) interaction. J Biol Chem 2001;276(31): 29375-29381

12 Trivedi V, Boire A, Tchernychev B, et al. Platelet matrix metalloprotease- 1 mediates thrombogenesis by activating PAR1 at a cryptic ligand site. Cell 2009;137(02):332-343

13 Falcinelli E, Guglielmini G, Torti M, Gresele P. Intraplatelet signaling mechanisms of the priming effect of matrix metalloproteinase-2 on platelet aggregation. J Thromb Haemost 2005; 3(11):2526-2535

14 Villeneuve J, Block A, Le Bousse-Kerdilès MC, Lepreux S, Nurden P, Ripoche J, Nurden AT. Tissue inhibitors of matrix metalloproteinases in platelets and megakaryocytes: a novel organization for these secreted proteins. Exp Hematol 2009;37:849-856

15 Sawicki G, Sanders EJ, Salas E, Wozniak M, Rodrigo J, Radomski MW. Localization and translocation of MMP-2 during aggregation of human platelets. Thromb Haemost 1998;80(05):836-839

16 Falcinelli E, Giannini S, Boschetti E, Gresele P. Platelets release active matrix metalloproteinase- 2 in vivo in humans at a site of vascular injury: lack of inhibition by aspirin. $\mathrm{Br} \mathrm{J}$ Haematol 2007; 138(02):221-230

17 Fernandez-Patron C, Martinez-Cuesta MA, Salas E, et al. Differential regulation of platelet aggregation by matrix metalloproteinases-9 and -2. Thromb Haemost 1999;82(06):1730-1735

18 Guglielmini G, Appolloni V, Momi S, et al. Matrix metalloproteinase-2 enhances platelet deposition on collagen under flow conditions. Thromb Haemost 2016;115(02):333-343

19 Gresele P, Falcinelli E, Loffredo F, et al. Platelets release matrix metalloproteinase- 2 in the coronary circulation of patients with acute coronary syndromes: possible role in sustained platelet activation. Eur Heart J 2011;32(03):316-325

20 Nocella C, Cammisotto V, Bartimoccia S, et al. A novel role of MMP2 in regulating platelet NOX2 activation. Free Radic Biol Med 2020;152:355-362

21 Mastenbroek TG, Feijge MA, Kremers RM, et al. Platelet-associated matrix metalloproteinases regulate thrombus formation and exert local collagenolytic activity. Arterioscler Thromb Vasc Biol 2015;35(12):2554-2561

22 Falcinelli E, Bury L, Tolley N, et al. Response: MMP-9 in platelets: maybe, maybe not. Blood 2011;118:6471-6473

23 Kälvegren H, Jönsson S, Jonasson L. Release of matrix metalloproteinases-1 and -2 , but not -9 , from activated platelets measured by enzyme-linked immunosorbent assay. Platelets 2011;22(08):572-578

24 Nakamura T, Ebihara I, Shimada N, Shoji H, Koide H. Modulation of plasma metalloproteinase-9 concentrations and peripheral blood monocyte mRNA levels in patients with septic shock: effect of fiber-immobilized polymyxin B treatment. Am J Med Sci 1998;316(06):355-360

25 Wang J, Ye Y, Wei G, et al. Matrix metalloproteinase 12 facilitated platelet activation by shedding carcinoembryonic antigen related cell adhesion molecule 1. Biochem Biophys Res Commun 2017;486(04):1103-1109

26 Amar S, Smith L, Fields GB. Matrix metalloproteinase collagenolysis in health and disease. Biochim Biophys Acta Mol Cell Res 2017;1864(11, Pt A)1940-1951

27 Howes JM, Pugh N, Knäuper V, Farndale RW. Modified platelet deposition on matrix metalloproteinase 13 digested collagen I. J Thromb Haemost 2015;13(12):2253-2259

28 Howes JM, Pugh N, Hamaia SW, et al. MMP-13 binds to platelet receptors $\alpha$ IIb $\beta 3$ and GPVI and impairs aggregation and thrombus formation. Res Pract Thromb Haemost 2018;2(02):370-379

29 Kazes I, Elalamy I, Sraer JD, Hatmi M, Nguyen G. Platelet release of trimolecular complex components MT1-MMP/TIMP2/MMP2: involvement in MMP2 activation and platelet aggregation. Blood 2000;96(09):3064-3069

30 Schmidt R, Bültmann A, Fischel S, et al. Extracellular matrix metalloproteinase inducer (CD147) is a novel receptor on platelets, activates platelets, and augments nuclear factor kappaB- dependent inflammation in monocytes. Circ Res 2008;102(03): 302-309

31 Sebastiano M, Momi S, Falcinelli E, Bury L, Hoylaerts M, Gresele P. MMP-2 mediates PAR1 biased signaling in human platelets: a novel mechanism regulating platelet activation. Blood 2017; 129:883-895

32 Brooks PC, Strömblad S, Sanders LC, et al. Localization of matrix metalloproteinase MMP-2 to the surface of invasive cells by interaction with integrin alpha $\mathrm{v}$ beta 3. Cell 1996;85(05): 683-693

33 Choi WS, Jeon OH, Kim HH, Kim DS. MMP-2 regulates human platelet activation by interacting with integrin alphallbbeta3. J Thromb Haemost 2008;6(03):517-523

34 Soslau G, Mason C, Lynch S, et al. Intracellular matrix metalloproteinase-2 (MMP-2) regulates human platelet activation via hydrolysis of talin. Thromb Haemost 2014;111(01):140-153

35 Radomski A, Stewart MW, Jurasz P, Radomski MW. Pharmacological characteristics of solid-phase von Willebrand factor in human platelets. Br J Pharmacol 2001;134(05):1013-1020

36 Lee YM, Lee JJ, Shen MY, Hsiao G, Sheu JR. Inhibitory mechanisms of activated matrix metalloproteinase-9 on platelet activation. Eur J Pharmacol 2006;537(1-3):52-58

37 Sheu JR, Fong TH, Liu CM, et al. Expression of matrix metalloproteinase- 9 in human platelets: regulation of platelet activation in in vitro and in vivo studies. Br J Pharmacol 2004;143(01): 193-201

38 Momi S, Sebastiano M, Falcinelli E, Gresele P. Matrix metalloproteinase-13 (MMP-13) is a novel regulator of platelet activation and in vivo thrombus formation. Blood Transfus 2018;16 (Suppl 4)s246

39 Seizer P, Borst O, Langer HF, et al. EMMPRIN (CD147) is a novel receptor for platelet GPVI and mediates platelet rolling via GPVIEMMPRIN interaction. Thromb Haemost 2009;101(04):682-686

40 Seizer P, Ungern-Sternberg SN, Schönberger T, et al. Extracellular cyclophilin A activates platelets via EMMPRIN (CD147) and PI3K/Akt signaling, which promotes platelet adhesion and thrombus formation in vitro and in vivo. Arterioscler Thromb Vasc Biol 2015;35(03):655-663

41 Momi S, Falcinelli E, Giannini S, et al. Loss of matrix metalloproteinase 2 in platelets reduces arterial thrombosis in vivo. J Exp Med 2009;206(11):2365-2379

42 Casscells W, Naghavi M, Willerson JT. Vulnerable atherosclerotic plaque: a multifocal disease. Circulation 2003;107(16): 2072-2075

43 Siemianowicz K, Gminski J, Goss M, et al. Influence of elastinderived peptides on metalloprotease production in endothelial cells. Exp Ther Med 2010;1(06):1057-1060

44 Pyo R, Lee JK, Shipley JM, et al. Targeted gene disruption of matrix metalloproteinase-9 (gelatinase B) suppresses development of experimental abdominal aortic aneurysms. J Clin Invest 2000; 105(11):1641-1649

45 Longo GM, Xiong W, Greiner TC, Zhao Y, Fiotti N, Baxter BT. Matrix metalloproteinases 2 and 9 work in concert to produce aortic aneurysms. J Clin Invest 2002;110(05):625-632

46 Davis V, Persidskaia R, Baca-Regen L, et al. Matrix metalloproteinase- 2 production and its binding to the matrix are increased in abdominal aortic aneurysms. Arterioscler Thromb Vasc Biol 1998;18(10):1625-1633

47 Xiong W, Knispel R, MacTaggart J, Greiner TC, Weiss SJ, Baxter BT. Membrane-type 1 matrix metalloproteinase regulates macrophage-dependent elastolytic activity and aneurysm formation in vivo. J Biol Chem 2009;284(03):1765-1771

48 Owens AP III, Edwards TL, Antoniak S, et al. Platelet inhibitors reduce rupture in a mouse model of established abdominal aneurysm. Arterioscler Thromb Vasc Biol 2015;35(09): 2032-2041

49 Momi S, Falcinelli E, Gresele P. Blood cells-derived matrix metalloproteinase (MMP)-2 contributes to abdominal aortic aneurism 
(AAA) development in a mouse model of hypertension/hypercholesterolemia. Journal of Thrombosis and Haemostasis 2015; 13(Suppl. 2):62-63 (abstract AS 174)

50 Rahman M, Zhang S, Chew M, Syk I, Jeppsson B, Thorlacius H. Platelet shedding of CD40L is regulated by matrix metalloproteinase-9 in abdominal sepsis. J Thromb Haemost 2013;11(07): 1385-1398

51 Kerr BA, McCabe NP, Feng W, Byzova TV. Platelets govern premetastatic tumor communication to bone. Oncogene 2013;32 (36):4319-4324

52 Fanjul-Fernández M, Folgueras AR, Fueyo A, et al. Matrix metalloproteinase MMP-1a is dispensable for normal growth and fertility in mice and promotes lung cancer progression by modulating inflammatory responses. J Biol Chem 2013;288 (20):14647-14656

53 Huet E, Gabison E, Vallee B, et al. Deletion of extracellular matrix metalloproteinase inducer/CD147 induces altered cardiac extracellular matrix remodeling in aging mice. J Physiol Pharmacol 2015;66(03):355-366

54 Cognasse F, Hamzeh-Cognasse H, Chabert A, et al. Streptococcus sanguinis-induced cytokine and matrix metalloproteinase-1 release from platelets. BMC Immunol 2014;15:15

55 Malik J, Stulc T, Ceska R. Matrix metalloproteinases in isolated hypercholesterolemia. Int Angiol 2005;24(03):300-303

56 Visse R, Nagase H. Matrix metalloproteinases and tissue inhibitors of metalloproteinases: structure, function, and biochemistry. Circ Res 2003;92(08):827-839

57 Stetler-Stevenson WG. Tissue inhibitors of metalloproteinases in cell signaling: metalloproteinase-independent biological activities. Sci Signal 2008;1(27):re6

58 Lenti M, Falcinelli E, Pompili M, et al. Matrix metalloproteinase-2 of human carotid atherosclerotic plaques promotes platelet activation. Correlation with ischaemic events. Thromb Haemost 2014;111(06):1089-1101

59 Lerner A, Neidhöfer S, Reuter S, Matthias T. MMP3 is a reliable marker for disease activity, radiological monitoring, disease outcome predictability, and therapeutic response in rheumatoid arthritis. Best Pract Res Clin Rheumatol 2018;32(04): 550-562

60 Lee JM, Kronbichler A, Park SJ, et al. Association between serum matrix metalloproteinase- (MMP-) 3 levels and systemic lupus erythematosus: a meta-analysis. Dis Markers 2019; 2019:9796735

61 Hu W, Wei R, Wang L, Lu J, Liu H, Zhang W. Correlations of MMP1, MMP-3, and MMP-12 with the degree of atherosclerosis, plaque stability and cardiovascular and cerebrovascular events. Exp Ther Med 2018;15(02):1994-1998

62 Boilard E, Nigrovic PA, Larabee K, et al. Platelets amplify inflammation in arthritis via collagen-dependent microparticle production. Science 2010;327(5965):580-583

63 Linge P, Fortin PR, Lood C, Bengtsson AA, Boilard E. The nonhaemostatic role of platelets in systemic lupus erythematosus. Nat Rev Rheumatol 2018;14(04):195-213

64 Chatterjee M, Gawaz M. Platelets in atherosclerosis. In: Gresele P, Kleiman NS, Lopez JA, Page CP, eds. Platelets in Thrombotic and Non-Thrombotic Disorders: Pathophysiology, Pharmacology and Therapeutics: An Update. Springer International Publishing; 2017:993-1013

65 Menchén L, Marín-Jiménez I, Arias-Salgado EG, et al. Matrix metalloproteinase 9 is involved in Crohn's disease-associated platelet hyperactivation through the release of soluble CD40 ligand. Gut 2009;58(07):920-928

66 Fernández Bello I, Álvarez MT, López-Longo FJ, et al. Platelet soluble CD40L and matrix metalloproteinase 9 activity are proinflammatory mediators in Behçet disease patients. Thromb Haemost 2012;107(01):88-98

67 Giannini S, Falcinelli E, Bury L, et al. Interaction with damaged vessel wall in vivo in humans induces platelets to express CD40L resulting in endothelial activation with no effect of aspirin intake. Am J Physiol Heart Circ Physiol 2011;300(06): H2072-H2079

68 Cimmino G, Ragni M, Cirillo P, et al. C-reactive protein induces expression of matrix metalloproteinase-9: a possible link between inflammation and plaque rupture. Int J Cardiol 2013;168 (02):981-986

69 Schulz C, von Brühl ML, Barocke V, et al. EMMPRIN (CD147) basigin) mediates platelet-monocyte interactions in vivo and augments monocyte recruitment to the vascular wall. J Thromb Haemost 2011;9(05):1007-1019

70 Schmidt R, Bültmann A, Ungerer M, et al. Extracellular matrix metalloproteinase inducer regulates matrix metalloproteinase activity in cardiovascular cells: implications in acute myocardial infarction. Circulation 2006;113(06):834-841

71 Seizer P, Schönberger T, Schött M, et al. EMMPRIN and its ligand cyclophilin A regulate MT1-MMP, MMP-9 and M-CSF during foam cell formation. Atherosclerosis 2010;209(01):51-57

72 Major TC, Liang L, Lu X, Rosebury W, Bocan TM. Extracellular matrix metalloproteinase inducer (EMMPRIN) is induced upon monocyte differentiation and is expressed in human atheroma. Arterioscler Thromb Vasc Biol 2002;22(07):1200-1207

73 Pennings GJ, Yong AS, Wong C, et al. Circulating levels of soluble EMMPRIN (CD147) correlate with levels of soluble glycoprotein VI in human plasma. Platelets 2014;25(08):639-642

74 Coussens LM, Fingleton B, Matrisian LM. Matrix metalloproteinase inhibitors and cancer: trials and tribulations. Science 2002; 295(5564):2387-2392

75 Raffetto JD, Khalil RA. Matrix metalloproteinases and their inhibitors in vascular remodeling and vascular disease. Biochem Pharmacol 2008;75(02):346-359

76 Prescott MF, Sawyer WK, Von Linden-Reed J, et al. Effect of matrix metalloproteinase inhibition on progression of atherosclerosis and aneurysm in LDL receptor-deficient mice overexpressing MMP-3, MMP-12, and MMP-13 and on restenosis in rats after balloon injury. Ann N Y Acad Sci 1999;878:179-190

77 Johnson JL, Fritsche-Danielson R, Behrendt M, et al. Effect of broad-spectrum matrix metalloproteinase inhibition on atherosclerotic plaque stability. Cardiovasc Res 2006;71(03): 586-595

78 Hudson MP, Armstrong PW, Ruzyllo W, et al. Effects of selective matrix metalloproteinase inhibitor (PG-116800) to prevent ventricular remodeling after myocardial infarction: results of the PREMIER (Prevention of Myocardial Infarction Early Remodeling) trial. J Am Coll Cardiol 2006;48(01):15-20

79 Peterson JT. Matrix metalloproteinase inhibitor development and the remodeling of drug discovery. Heart Fail Rev 2004;9 (01):63-79

80 Camp TM, Tyagi SC, Aru GM, Hayden MR, Mehta JL, Tyagi SC. Doxycycline ameliorates ischemic and border-zone remodeling and endothelial dysfunction after myocardial infarction in rats. J Heart Lung Transplant 2004;23(06):729-736

81 Manning MW, Cassis LA, Daugherty A. Differential effects of doxycycline, a broad-spectrum matrix metalloproteinase inhibitor, on angiotensin II-induced atherosclerosis and abdominal aortic aneurysms. Arterioscler Thromb Vasc Biol 2003;23(03): 483-488

82 Axisa B, Loftus IM, Naylor AR, et al. Prospective, randomized, double-blind trial investigating the effect of doxycycline on matrix metalloproteinase expression within atherosclerotic carotid plaques. Stroke 2002;33(12):2858-2864

83 Brown DL, Desai KK, Vakili BA, Nouneh C, Lee HM, Golub LM. Clinical and biochemical results of the metalloproteinase inhibition with subantimicrobial doses of doxycycline to prevent acute coronary syndromes (MIDAS) pilot trial. Arterioscler Thromb Vasc Biol 2004;24(04):733-738

84 Cerisano G, Buonamici P, Valenti R, et al. Early short-term doxycycline therapy in patients with acute myocardial infarction 
and left ventricular dysfunction to prevent the ominous progression to adverse remodelling: the TIPTOP trial. Eur Heart J 2014;35(03):184-191

85 Switzer JA, Hess DC, Ergul A, et al. Matrix metalloproteinase-9 in an exploratory trial of intravenous minocycline for acute ischemic stroke. Stroke 2011;42(09):2633-2635

86 Johnson JL, Devel L, Czarny B, et al. A selective matrix metalloproteinase-12 inhibitor retards atherosclerotic plaque development in apolipoprotein E-knockout mice. Arterioscler Thromb Vasc Biol 2011;31(03):528-535

87 Scannevin RH, Alexander R, Haarlander TM, et al. Discovery of a highly selective chemical inhibitor of matrix metalloproteinase9 (MMP-9) that allosterically inhibits zymogen activation. J Biol Chem 2017;292(43):17963-17974

88 Jacobsen JA, Major Jourden JL, Miller MT, Cohen SM. To bind zinc or not to bind zinc: an examination of innovative approaches to improved metalloproteinase inhibition. Biochim Biophys Acta 2010;1803(01):72-94

89 Gu Z, Cui J, Brown S, et al. A highly specific inhibitor of matrix metalloproteinase-9 rescues laminin from proteolysis and neurons from apoptosis in transient focal cerebral ischemia. J Neurosci 2005;25(27):6401-6408

90 Chen S, Chen Z, Cui J, et al. Early abrogation of gelatinase activity extends the time window for tPA thrombolysis after embolic focal cerebral ischemia in mice. eNeuro 2018;5(03): ENEURO.0391-17.2018

91 Pahk K, Joung C, Song HY, Kim S, Kim WK. SP-8356, a novel inhibitor of CD147-cyclophilin A interactions, reduces plaque progression and stabilizes vulnerable plaques in ApoE-deficient mice. Int J Mol Sci 2019;21(01):95

92 Pahk K, Noh H, Joung C, et al. A novel CD147 inhibitor, SP-8356, reduces neointimal hyperplasia and arterial stiffness in a rat model of partial carotid artery ligation. J Transl Med 2019;17(01):274

93 Yamamoto D, Takai S, Miyazaki M. Prediction of interaction mode between a typical ACE inhibitor and MMP-9 active site. Biochem Biophys Res Commun 2007;354(04):981-984

94 Kuntze LB, Antonio RC, Izidoro-Toledo TC, Meschiari CA, TanusSantos JE, Gerlach RF. Captopril and lisinopril only inhibit matrix metalloproteinase-2 (MMP-2) activity at millimolar concentrations. Basic Clin Pharmacol Toxicol 2014;114(03):233-239

95 Yamamoto D, Takai S, Miyazaki M. Inhibitory profiles of captopril on matrix metalloproteinase-9 activity. Eur J Pharmacol 2008; 588(2-3):277-279

96 Pfeffer MA. ACE inhibitors in acute myocardial infarction: patient selection and timing. Circulation 1998;97(22):2192-2194

97 Yamamoto D, Takai S. Pharmacological implications of MMP-9 inhibition by ACE inhibitors. Curr Med Chem 2009;16(11):1349-1354

98 Liang C, Wu ZG, Ding J, et al. Losartan inhibited expression of matrix metalloproteinases in rat atherosclerotic lesions and angiotensin II-stimulated macrophages. Acta Pharmacol Sin 2004;25(11):1426-1432

99 Yang D, Ma S, Li D, Tang B, Yang Y. Angiotensin II receptor blockade improves matrix metalloproteinases/tissue inhibitor of matrix metalloproteinase- 1 balance and restores fibronectin expression in rat infarcted myocardium. Biochem Biophys Res Commun 2009;388(03):606-611

100 Miyazaki S, Kasai T, Miyauchi K, et al. Changes of matrix metalloproteinase-9 level is associated with left ventricular remodel- ing following acute myocardial infarction among patients treated with trandolapril, valsartan or both. Circ J 2010;74 (06):1158-1164

101 Senzaki H, Paolocci N, Gluzband YA, et al. $\beta$-blockade prevents sustained metalloproteinase activation and diastolic stiffening induced by angiotensin II combined with evolving cardiac dysfunction. Circ Res 2000;86(07):807-815

102 Rizzi E, Guimaraes DA, Ceron CS, et al. $\beta 1$-Adrenergic blockers exert antioxidant effects, reduce matrix metalloproteinase activity, and improve renovascular hypertension-induced cardiac hypertrophy. Free Radic Biol Med 2014;73:308-317

103 Cimmino G, Ibanez B, Giannarelli C, et al. Carvedilol administration in acute myocardial infarction results in stronger inhibition of early markers of left ventricular remodeling than metoprolol. Int J Cardiol 2011;153(03):256-261

104 Song G, Hennessy M, Zhao YL, et al. Adrenoceptor blockade alters plasma gelatinase activity in patients with heart failure and MMP-9 promoter activity in a human cell line (ECV304). Pharmacol Res 2006;54(01):57-64

105 Crisby M, Nordin-Fredriksson G, Shah PK, Yano J, Zhu J, Nilsson J. Pravastatin treatment increases collagen content and decreases lipid content, inflammation, metalloproteinases, and cell death in human carotid plaques: implications for plaque stabilization. Circulation 2001;103(07):926-933

106 Li J, Zhao SP, Peng DQ, Xu ZM, Zhou HN. Early effect of pravastatin on serum soluble CD40L, matrix metalloproteinase-9, and Creactive protein in patients with acute myocardial infarction. Clin Chem 2004;50(09):1696-1699

107 Nakaya R, Uzui H, Shimizu H, et al. Pravastatin suppresses the increase in matrix metalloproteinase-2 levels after acute myocardial infarction. Int J Cardiol 2005;105(01):67-73

108 Yasuda S, Miyazaki S, Kinoshita H, et al. Enhanced cardiac production of matrix metalloproteinase- 2 and -9 and its attenuation associated with pravastatin treatment in patients with acute myocardial infarction. Clin Sci (Lond) 2007;112(01):43-49

109 Ichihara S, Noda A, Nagata K, et al. Pravastatin increases survival and suppresses an increase in myocardial matrix metalloproteinase activity in a rat model of heart failure. Cardiovasc Res 2006; 69(03):726-735

110 Jurasz P, Sawicki G, Duszyk M, et al. Matrix metalloproteinase 2 in tumor cell-induced platelet aggregation: regulation by nitric oxide. Cancer Res 2001;61(01):376-382

111 Marturano A, Hendrickx MLV, Falcinelli E, et al. Development of anti-matrix metalloproteinase-2 (MMP-2) nanobodies as potential therapeutic and diagnostic tools. Nanomedicine (Lond) 2020;24:102103

112 Momi S, Wiwanitkit V. Phylogeny of blood platelets. In: Gresele P, Kleiman NS, Lopez JA, Page CP, eds. Platelets in Thrombotic and Non-Thrombotic Disorders: Pathophysiology, Pharmacology and Therapeutics: an Update. Springer International Publishing; 2017:11-20

113 Das S, Mandal M, Chakraborti T, Mandal A, Chakraborti S. Structure and evolutionary aspects of matrix metalloproteinases: a brief overview. Mol Cell Biochem 2003;253(12):31-40

114 Gresele P, Falcinelli E, Momi S. Potentiation and priming of platelet activation: a potential target for antiplatelet therapy. Trends Pharmacol Sci 2008;29(07):352-360 